\title{
Evolution of a Super Cloud Cluster and the Associated Wind Fields Observed over the Indonesian Maritime Continent during the First CPEA Campaign
}

\author{
Yoshiaki SHIBAGAKI \\ Faculty of Information and Communication Engineering, Osaka Electro-Communication University, \\ Neyagawa, Japan \\ Toshiaki KOZU, Toyoshi SHIMOMAI \\ Faculty of Science and Engineering, Shimane University, Matsue, Japan \\ Shuichi MORI \\ Institute of Observational Research for Global Change (IORGC), \\ Japan Agency for Marine-Earth Science and Technology (JAMSTEC), Yokosuka, Japan \\ Fumie MURATA \\ Research Institute for Humanity and Nature, Kyoto, Japan
}

Yasushi FUJIYOSHI

Institute of Low Temperature Science, Hokkaido University, Sapporo, Japan / Frontier Research Center for Global Change (FRCGC), Japan Agency for Marine-Earth Science and Technology (JAMSTEC), Yokohama, Japan

\section{Hiroyuki HASHIGUCHI and Shoichiro FUKAO}

Research Institute for Sustainable Humanosphere (RISH), Kyoto University, Uji, Japan

(Manuscript received 7 November 2005, in final form 9 April 2006)

\begin{abstract}
A special tropospheric observation was conducted during 10 April-09 May 2004 as a part of the first campaign of the Coupling Processes in the Equatorial Atmosphere (CPEA-I), using upper soundings at seven stations in/around Sumatera, and weather radar and wind profilers at Kototabang $\left(\mathrm{KT} ; 100.32^{\circ} \mathrm{E}\right.$, $0.20^{\circ} \mathrm{S}, 865 \mathrm{~m}$ above mean sea level), West Sumatera. A super cloud cluster (SCC) with a westerly wind burst (WWB) propagated eastward over the Indonesian Maritime Continent during 04-07 May. In the present report, we examine the evolution of that SCC and the associated wind behavior in detail, using
\end{abstract}

Corresponding author: Yoshiaki Shibagaki, Faculty of Information and Communication Engineering, Osaka Electro-Communication University, 18-

8 Hatsu-cho, Neyagawa, Osaka 572-8530, Japan.

E-mail: sibagaki@maelab.osakac.ac.jp

(C) 2006, Meteorological Society of Japan 
Geostationary Operational Environmental Satellite (GOES-9) Infrared (IR) data and CPEA observations. During the analysis period, the SCC developed over the eastern Indian Ocean, decayed rapidly as it reached Sumatera, and re-developed over Kalimantan. The eastward propagation of SCC resulted from the successive formation of meso-scale cloud clusters (CCs) with westward propagation. The transition of the SCC was related to the evolution of CCs. A CC generated over Sumatera began to diminish as the WWB arrives at a mountain range in western Sumatera, but it dominated in/around the mountain range for $\sim 9$ hours. From upper sounding data aligned along the equator, it was found that the migration speed of the WWB over Sumatera was approximately half that over the sea region between Sumatera and Kalimantan, due to the orography of the Indonesian Maritime Continent. In western Sumatera, the peak height of the WWB at the mountain range ascended $1.5 \mathrm{~km}$ from that on the windward side. This shows that the eastward migration of the WWB was intercepted by the mountain range. The orographic influence on the WWB is considered to persist during the retention of the CC in its vicinity. Further, we reveal features of the orographic precipitation associated with the WWB and the detailed wind structure inside the SCC over the mountain range, from radar observations at KT.

\section{Introduction}

In the tropics, the dominant intraseasonal variation (ISV), with a period of 30-60 days, is characterized by the eastward propagation of a large-scale cloud system with zonal wavenumber of 1-2 (e.g., Madden and Julian 1994). The cloud system is recognized as an envelope of super cloud clusters (SCCs) with a horizontal scale of 2000-4000 km (Nakazawa 1988; Lau et al. 1991). It is also known that a low-level strong westerly wind region migrates with the eastward propagation of SCCs (e.g., Rui and Wang 1990).

Many authors have reported that SCCs evolve over the Indonesian Maritime Continent as they propagate from the eastern Indian Ocean to the western Pacific Ocean (e.g., Nitta et al. 1992; Sui and Lau 1992; Weickmann and Khalsa 1990). For example, Nitta et al. (1992) showed that a developing SCC over the eastern Indian Ocean rapidly decayed as it reached Sumatera, and then re-developed over the western Pacific Ocean. They also pointed out that the SCC decay resulted from the blocking effect of elevated topography over Sumatera on a strong low-level westerly wind. Such a transitional mechanism of SCCs over the Indonesian Maritime Continent could be made clear by wind observations with sufficient temporal and spatial resolution.

The equatorial atmosphere radar (EAR) facility was constructed in 2001 at Kototabang (KT; $100.32^{\circ} \mathrm{E}, 0.20^{\circ} \mathrm{S}, 865 \mathrm{~m}$ above MSL), West Sumatera. The EAR enables us to obtain continuously a vertical profile of three wind compo- nents $(\mathrm{U}, \mathrm{V}$, and $\mathrm{W})$ in the whole troposphere. L-band boundary layer radar (BLR) and Xband weather radar have been also installed there. Based on these radar observations, Seto et al. (2004) studied the vertical structure of wind fields through the inactive phase, active phase, and post-westerly wind burst phase of an ISV. Shibagaki et al. (2006) also showed an environmental wind associated with an SCC and a detailed wind change in relation to the evolution and propagation of a meso-scale convective system in the SCC. However, wind fields associated with the evolution of the SCC over Sumatera have not been discussed in these studies, because of the limited area under observation.

A special tropospheric observation was conducted during 10 April-09 May 2004 as a part of the first campaign of the Coupling Processes in the Equatorial Atmosphere (CPEA-I; MarchMay 2004); this will be referred to as 'the CPEA campaign'. During this period, upper sounding observations were performed at seven stations in/around Sumatera, in addition to the groundbased radar observations at KT (Fukao 2006). In the latter half of the CPEA campaign, satellite cloud data indicates that three SCCs associated with an ISV reached the equatorial region of Sumatera. The third of these SCCs was accompanied by a westerly wind burst (WWB), defined as a low-level strong westerly wind.

The main purpose of this study is to demonstrate the evolution of an SCC and the associated wind behavior under the influence of surface topography over Sumatera, using 


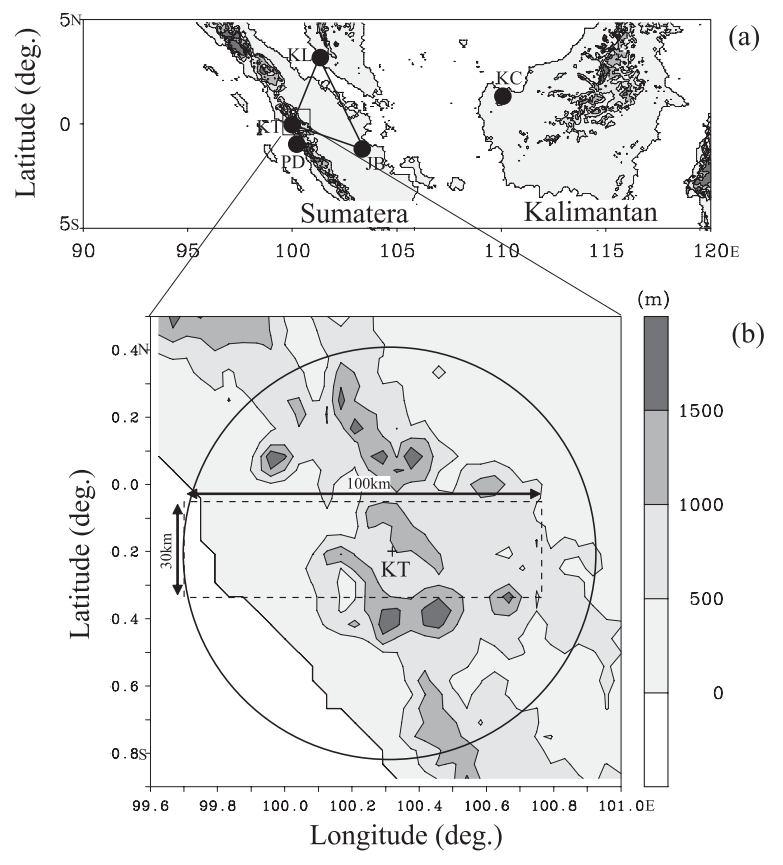

Fig. 1. a) Surface topography of the Indonesian Maritime Continent. The map in panel (b) is an enlargement of the square area in panel (a). In panel (a), black-enclosed circles show upper sounding stations at Kototabang (KT), Kuala Lumpur (KL), Jambi (JB), Kuching (KC) and Padang (PD). The triangle enclosed by $\mathrm{KT}, \mathrm{KL}$ and JB is the analysis area for divergence in Fig. 9. In panel (b), the plus mark is the location of the EAR observatory at KT. The large circle marks the observational area of the X-band weather radar. The $\mathrm{X}$-band weather radar data was used mainly in the rectangular area within the circle, because of the orographic shadows surrounding KT.

satellite data, upper sounding network data, and ground-based radar observation data at KT.

\section{CPEA special observation data}

\subsection{Upper sounding observations}

Figure 1a presents the surface topography of Indonesian Maritime Continent. A mountain range higher than $500 \mathrm{~m}$ is located along the western edge of Sumatera. In the CPEA campaign, upper sounding observations were carried out at seven stations in Indonesia, Malay- sia, and Singapore (Fukao 2006). In this study, we used upper sounding data from five stations; KT, Jambi (JB), Kuala Lumpur (KL), Kuching (KC), and Padang (PD), plotted by black-enclosed circles. Locations and temporal data intervals at each station are also listed in Table 1. Stations are separated by more than $360 \mathrm{~km}$, except for PD and KT, which are located in the coastal area to the west of the mountain range and the mountainous area, respectively.

From the upper sounding network data at $\mathrm{KL}, \mathrm{KT}$, and $\mathrm{JB}$, the vertical $p$-velocity was computed by the upward integration of the divergence using the continuity equation. The vertical $p$-velocity was calculated from $900 \mathrm{hPa}$ because $\mathrm{KT}$ is located at $865 \mathrm{~m}(\sim 900 \mathrm{hPa})$ above MSL. The vertical $p$-velocity was corrected linearly at $100 \mathrm{hPa}$ as zero (O'Brien 1970). The area enclosed by the triangle in Fig. 1a is $7.2 \times 10^{4} \mathrm{~km}^{2}$.

\subsection{Ground-based radar observations at KT}

At KT, radar observations of X-band weather radar and two wind profiles of different types have been performed. In Fig. 1b, the large circle with a diameter of $120 \mathrm{~km}$ is the observation range of X-band weather radar. Constant Altitude of Plan Position Indicator (CAPPI) data was obtained at 10-min intervals. We used the CAPPI data mainly in the rectangular area $(100 \mathrm{~km}$ in east-west and $30 \mathrm{~km}$ in southnorth), because of the orographic shadows surrounding KT.

The VHF-band wind profiler named EAR continuously provides the vertical profiles of three components of the wind field, including vertical velocity, over altitudes from 2 to $20 \mathrm{~km}$ above MSL (Fukao et al. 2003). The time and height resolutions are $90 \mathrm{~s}$ and $150 \mathrm{~m}$.

The L-band wind profiler (BLR) can obtain vertical profiles of horizontal winds over altitudes from $1.5-3.0 \mathrm{~km}$ in clear-air conditions. In rainy conditions, the observation altitude of BLR increases up to $10 \mathrm{~km}$ (Teshiba et al. 2001). Time and height resolutions are $60 \mathrm{~s}$ and $150 \mathrm{~m}$. Reflectivity observed by BLR is also employed to investigate the vertical structure of precipitation systems.

In the CPEA campaign, another X-band weather radar with Doppler capability was also operated $20 \mathrm{~km}$ south of the EAR site (Kawa- 
Table 1. Location and launching frequency of upper sounding stations used in this study.

\begin{tabular}{|l|c|c|}
\hline Upper sounding stations & Location & Times per day \\
\hline (1) Kototabang $(\mathrm{KT})$ & $100.32^{\circ} \mathrm{E}, 0.20^{\circ} \mathrm{S}, 865 \mathrm{~m}$ above MSL & 4 \\
\hline (2) Jambi (JB) & $103.65^{\circ} \mathrm{E}, 1.60^{\circ} \mathrm{S}, 26 \mathrm{~m}$ above MSL & 4 \\
\hline (3) Kuala Lumpur $(\mathrm{KL})$ & $101.70^{\circ} \mathrm{E}, 2.73^{\circ} \mathrm{N}, 17 \mathrm{~m}$ above MSL & 4 \\
\hline (4) Kuching $(\mathrm{KC})$ & $110.33^{\circ} \mathrm{E}, 1.48^{\circ} \mathrm{N}, 22 \mathrm{~m}$ above MSL & 4 \\
\hline (5) Padang (PD) & $100.35^{\circ} \mathrm{E}, 0.88^{\circ} \mathrm{S}, 2 \mathrm{~m}$ above MSL & $2^{*}$ \\
\hline
\end{tabular}

*At PD, the launching frequency increases to 3 or 4 per day during SCC events.

shima et al. 2006). However, the radar data are not used in this study.

\subsection{Satellite data}

To examine the overall distribution of cloud systems from the central Indian Ocean to the western Pacific Ocean, daily outgoing longwave radiation (OLR) data is employed, with a $2.5^{\circ}$ longitude/latitude grid.

This study mainly uses hourly cloud top equivalent blackbody temperature (TBB) data from Geostationary Operational Environmental Satellite (GOES-9) Infrared (IR), recorded in a $0.05^{\circ}$ longitude/latitude grid. The TBB data reveal the fine structure of SCCs over/ around the Indonesian Maritime Continent.

\section{An overview of cloud systems and environmental wind during the CPEA campaign}

Figure 2 presents the longitude-latitude section of OLR data averaged from 10 April to 09 May 2004. During the CPEA campaign, cloud activity areas were concentrated over the eastern Indian Ocean and islands in the Indonesian Maritime Continent. Cloud activity was associated with the eastward propagation of an ISV from the central Indian Ocean $\left(\sim 60^{\circ} \mathrm{E}\right)$ to the western edge of the Pacific Ocean $\left(\sim 130^{\circ} \mathrm{E}\right)$.

Figure 3 presents the longitude-time section of 6-hourly $\mathrm{TBB}$ between $75^{\circ} \mathrm{E}$ and $125^{\circ} \mathrm{E}$, averaged over $2^{\circ} \mathrm{S}-2^{\circ} \mathrm{N}$, during the CPEA campaign. Over the eastern Indian Ocean (75$95^{\circ} \mathrm{E}$ ), westward-propagating cloud clusters predominate in the ISV. In the active cloud regions, three eastward-propagating SCCs with a speed of $10-15 \mathrm{~ms}^{-1}$ were found as shown by long arrows. They reached Sumatera on 23 April, 29 April, and 05 May. Successive SCCs are designated SCC1, SCC2, and SCC3. The eastward propagation of SCC1 and SCC2 became obscure to the east of Sumatera, while that of SCC3 was clearly seen over the Indonesian Maritime Continent. During the passage of SCCs, active clouds with a diurnal cycle were observed over Sumatera and Kalimantan.

Figure $4 \mathrm{a}$ presents the time-altitude section of zonal wind over the altitude range of 2$10 \mathrm{~km}$, observed with $\mathrm{EAR}$ at $\mathrm{KT}\left(100.32^{\circ} \mathrm{E}\right)$. A time series of low-level zonal wind averaged over altitudes of $1.5-2.0 \mathrm{~km}$, obtained by BLR, is also shown in Fig. 4b. From the cloud activity due to SCCs over Sumatera, the periods of 1022 April and 23 April-06 May in the CPEA

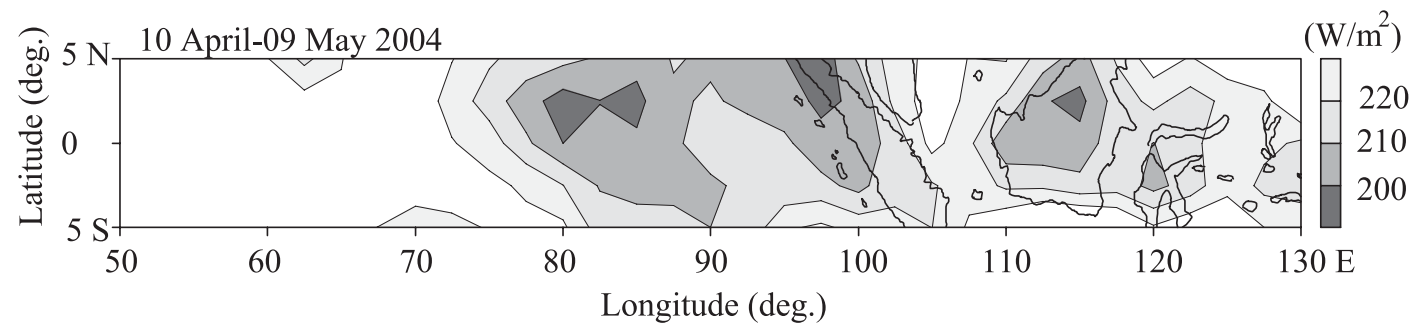

Fig. 2. Horizontal distribution of OLR averaged from 10 April to 09 May 2004. 


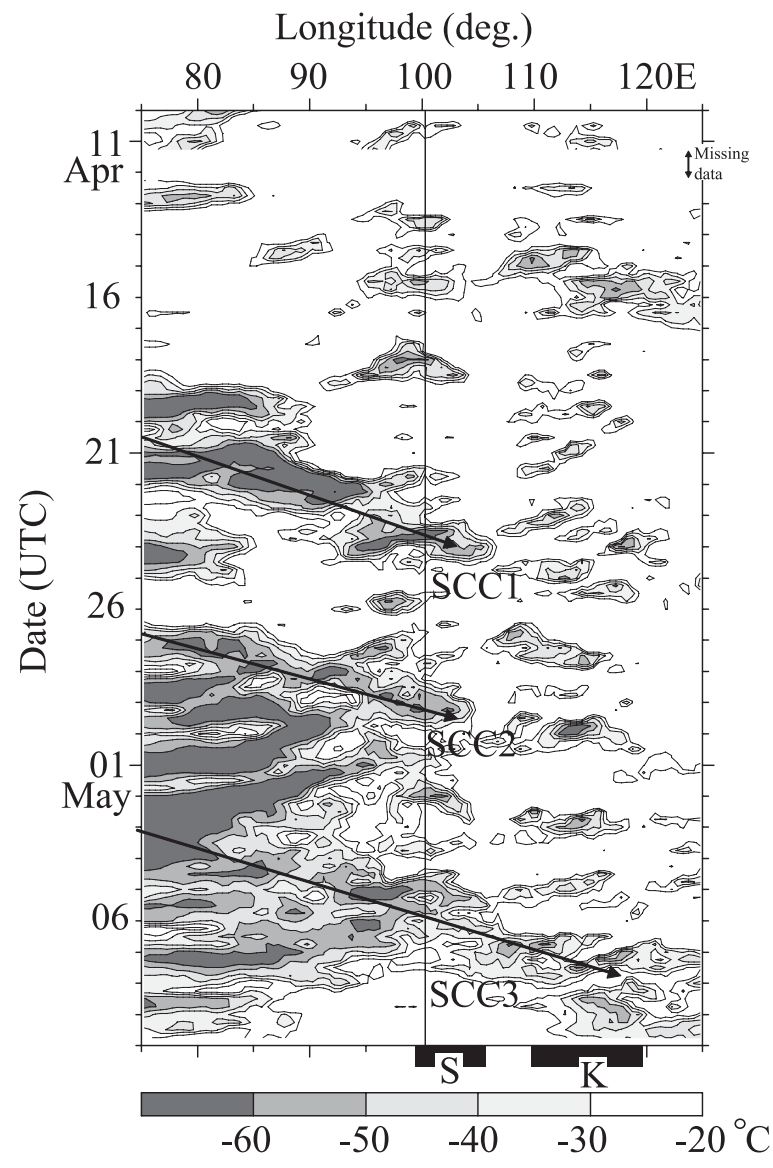

Fig. 3. Longitude-time section of 6-hourly TBB average over $2^{\circ} \mathrm{S}-2^{\circ} \mathrm{N}$ from 10 April to 09 May. Long arrows indicate the propagation of each SCC. Symbols of $\mathbf{S}$ and $\mathbf{K}$ represent Sumatera and Kalimantan.

campaign are defined as inactive and active phases of ISV, respectively.

In Fig. 4a, an environmental easterly wind is predominant in the middle and upper troposphere during the entire period. In the lower troposphere, westerly wind regions appear at intervals of 2-5 days in the environmental easterly wind. Such wind variation is also evident at low levels in Fig. 4b, except for 11-13 April.

In the inactive phase of ISV, a variation of clouds with a period of one day is seen over Sumatera, associated with the decrease of the low-level easterly wind before 15 April. An active cloud is also observed with the appearance of the low-level westerly wind on 18 April.

In the active phase of ISV, the low-level east-

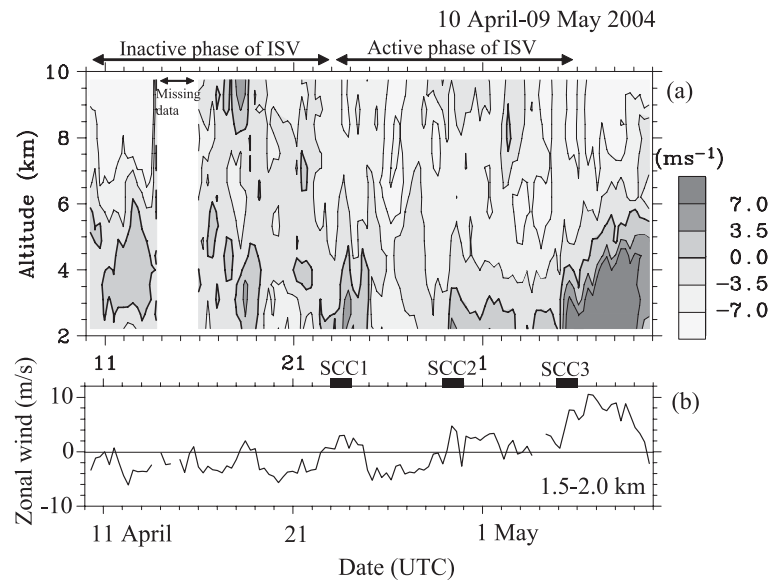

Fig. 4. (a) Time-altitude section of zonal wind observed by EAR in the altitude range of 2-10 km and (b) time series of low-level zonal wind averaged over altitudes of $1.5-2.0 \mathrm{~km}$ from BLR at $\mathrm{KT}$ from 10 April to 09 May. Time average of BLR and EAR data is at intervals of 6 hours.

erly wind changed to westerly with the passage of SCC1 and SCC2, while a westerly wind intensified at the passage of SCC3. After the passage of SCC3, a WWB region, identified as an intense westerly wind $\left(>7 \mathrm{~ms}^{-1}\right)$, ascended to an altitude of $4.5 \mathrm{~km}$. The cloud activity over Sumatera was suppressed due to the intrusion of dry air associated with the WWB (Murata et al. 2006).

In the present study, we focus on the SCC3 event in the active phase of ISV, indicating a well defined propagation over the Indonesian Maritime Continent. In the subsequent sections, the evolution process of SCC3 over Sumatera will be investigated.

\section{Evolution and internal structure of SCC3 over the Indonesian Maritime Continent}

Figure 5 presents 12-hourly maps of TBB over/around the Indonesian Maritime Continent from 1200 UTC 04 May to 1200 UTC 06 May. 0000 UTC is 0700 LST in Indonesia. The ellipse in each panel indicates the main part of SCC3 shown in Fig. 3 (hereafter simply called 'SCC3'). The propagation of SCC3 is indicated by the long arrow.

Over the eastern Indian Ocean, low-TBB 

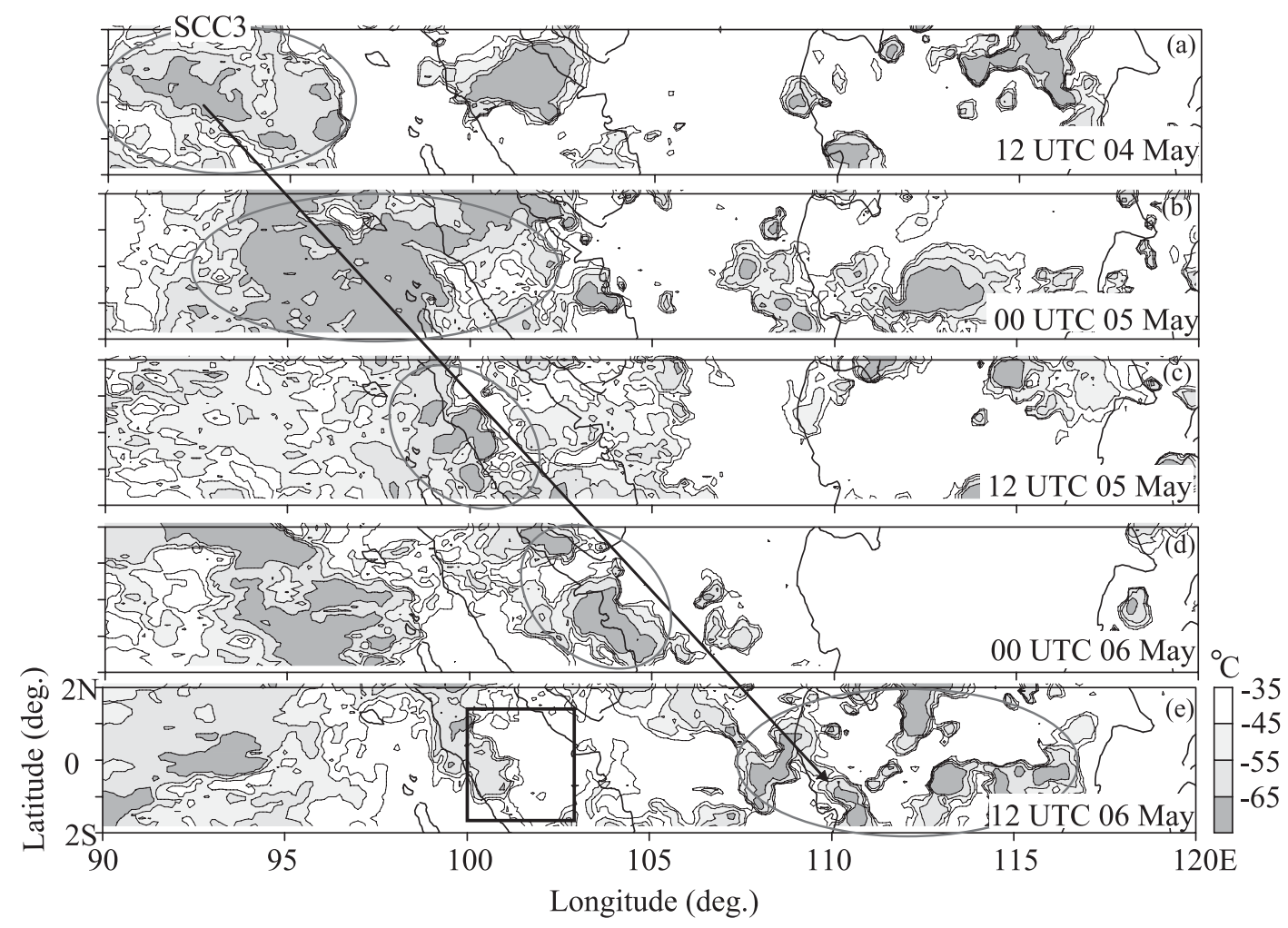

Fig. 5. 12-hourly maps of TBB over/around the Indonesian Maritime Continent from 1200 UTC 04 May to 1200 UTC 06 May. The ellipse in each panel indicates the main part of SCC3 shown in Fig. 3, and its propagation is shown by the long arrow. The square area in panel (e) is shown in the analysis area of Fig. 8. The plus mark is the location of KT. TBB data is averaged over $0.1^{\circ}$ grids.

areas $\left(<-65^{\circ} \mathrm{C}\right)$ in SCC3 significantly expanded as it approached Sumatera (Figs. 5a-b). However, the low-TBB areas rapidly diminished over Sumatera, and they were located in/ around western Sumatera (Fig. 5c). After 12 hours, the low-TBB areas shifted to eastern Sumatera (Fig. 5d). Then SCC3, composed of isolated low-TBB clouds, expanded over the entire Kalimantan region (Fig. 5e).

To facilitate understanding the evolution process of SCC3 in detail, Figure 6 shows the longitude-time section of 3-hourly TBB averaged over $2^{\circ} \mathrm{S}-2^{\circ} \mathrm{N}$, during 04-07 May. From this figure, it is evident that the eastward propagation of SCC3 results from the successive formation of sub-systems of SCC3 with westward propagation, as shown by white lines. The subsystems are referred to as CC1-6 in the order of their appearance.

CC1 is seen in SCC3 as it dominates the eastern Indian Ocean on 04 May. CC2 propa- gates westward from eastern Sumatera, and it develops significantly over the eastern Indian Ocean between 1800 UTC 04 May and 1200 UTC 05 May. With the development of CC2, CC3 forms around the east coast of Sumatera. It develops over the eastern Indian Ocean and persists to $\sim 80^{\circ} \mathrm{E}$ (see Fig. 3). At 0000 UTC 06 May, CC4 appears around the east coast of Sumatera, but its westward propagation is not obvious in comparison with other sub-systems of SCC3 in/around Sumatera. CC5 and CC6 are seen over Kalimantan after 1200 UTC 06 May. While CC5 develops over western Kalimantan, CC6 is observed over eastern Kalimantan.

The location and time on the development of these cloud clusters are coincident with the diurnal variation of cloud activity over the Indonesian Maritime Continent, as studied by Nitta and Sekine (1994). The internal structure of SCC3 is similar to that of SCCs over the western Pacific Ocean studied by Nakazawa (1988), 


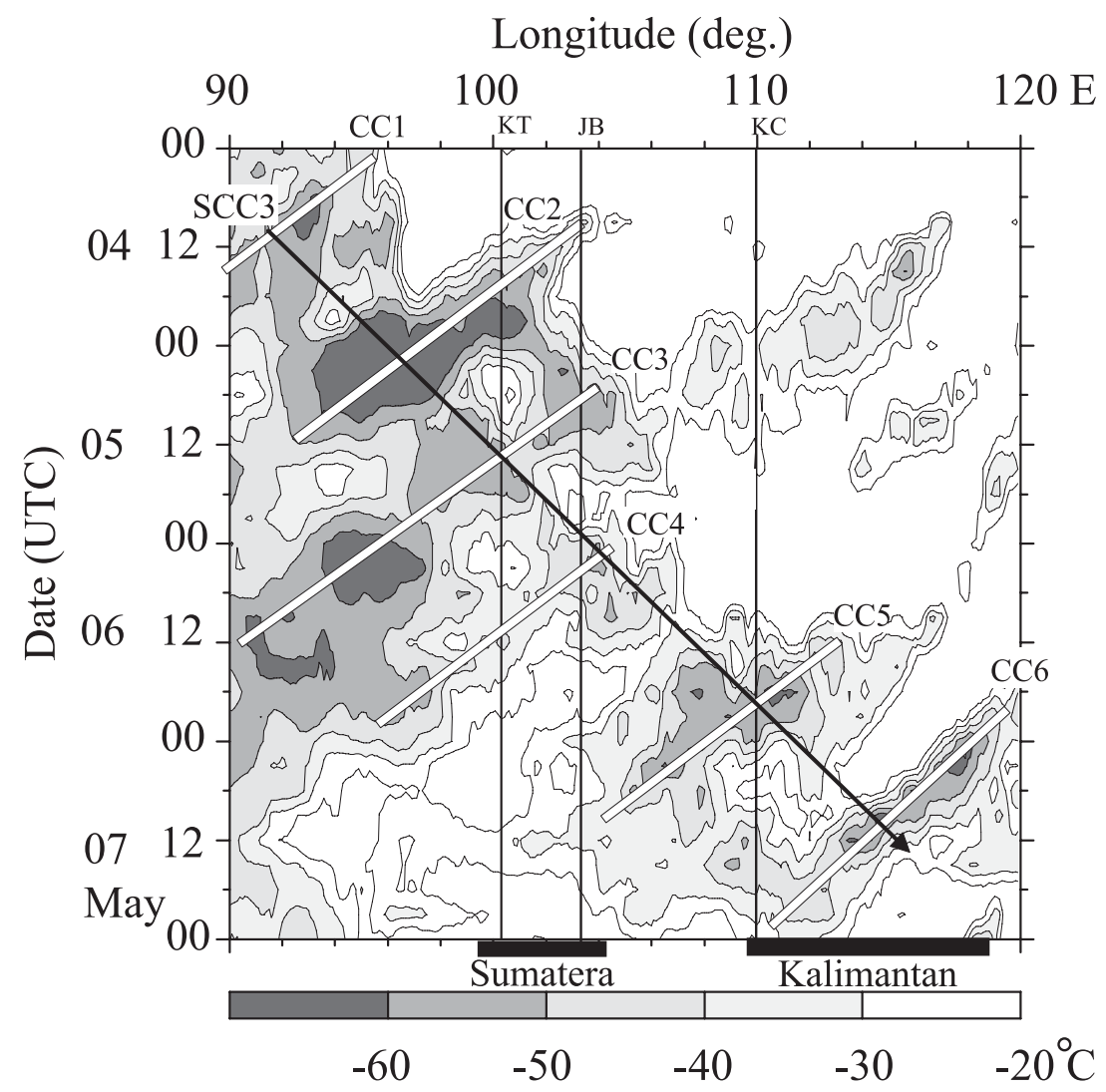

Fig. 6. Longitude-time section of 3-hourly TBB averaged over $2{ }^{\circ} \mathrm{S}-2^{\circ} \mathrm{N}$ during $04-07$ May. The long arrow indicates the propagation of SCC3. White lines show the propagation of sub-systems of SCC3. Thin black lines are the locations of KT, JB, and KC.

but the propagation speed of SCC3 varies in accordance with the evolution of cloud clusters with the diurnal cycle.

Figure 7 presents time variations of zonal wind at the $850-\mathrm{hPa}$ level ( $1.5 \mathrm{~km}$ in altitude) at $\mathrm{KT}\left(100.32^{\circ} \mathrm{E}\right)$, JB $\left(103.65^{\circ} \mathrm{E}\right)$, and $\mathrm{KC}$ $\left(110.33^{\circ} \mathrm{E}\right)$ in the longitudinal direction. After 1200 UTC 05 May, the low-level westerly wind at these stations successively increases to 6$8 \mathrm{~ms}^{-1}$ with the eastward propagation of SCC3. The large amplitude westerly wind is identified as a WWB. CC3 and WWB occur simultaneously at $\mathrm{KT}$, while the appearance of CC4 and CC5 precedes the arrival of WWB at JB and KC, respectively (see Fig. 6).

\section{Convective activities associated with SCC3 over Sumatera}

As mentioned in the previous section, subsystems of SCC3 (CC2, CC3, and CC4) ap- peared over Sumatera at intervals of one day, during 04-06 May. In this section, the characteristics of cloud activity and background vertical motion associated with SCC3 are described.

Figure 8 presents a time series of hourly TBB histogram at intervals of $5^{\circ} \mathrm{C}$ over the region

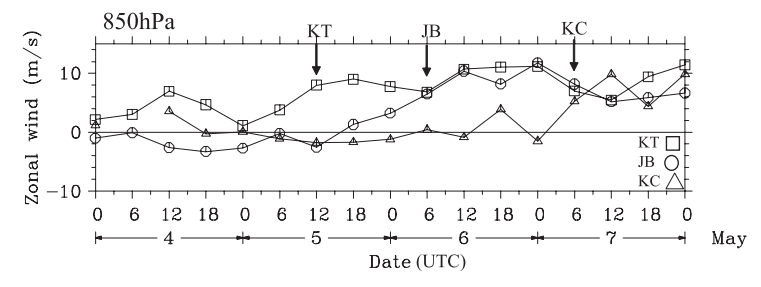

Fig. 7. Time variations of 6-hourly zonal wind at $850-\mathrm{hPa}$ level at $\mathrm{KT}\left(100.32^{\circ} \mathrm{E}\right)$, $\mathrm{JB}\left(103.65^{\circ} \mathrm{E}\right)$, and $\mathrm{KC}\left(110.33^{\circ} \mathrm{E}\right)$ during 04-07 May. The intensification of low-level westerly wind at each station is shown by the arrow. 


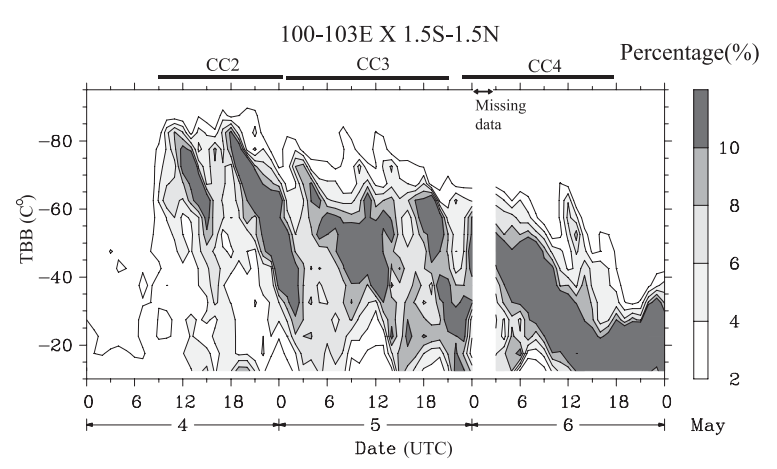

Fig. 8. Time series of TBB histogram at intervals of $5^{\circ} \mathrm{C}$ within the region 100 $103^{\circ} \mathrm{E} \times 1.5^{\circ} \mathrm{S}-1.5^{\circ} \mathrm{N}$ (square area in Fig. 5e) during 04-06 May. This figure indicates the vertical distribution of cloud-top height in sub-systems of SCC3. Periods that CC2, CC3, and CC4 passed over Sumatera in Fig. 6 are shown in the top of this panel.

$100-103^{\circ} \mathrm{E} \times 1.5^{\circ} \mathrm{S}-1.5^{\circ} \mathrm{N}$ (square area in Fig. 5e) during 04-06 May. This figure indicates the vertical distribution of cloud-top heights in these cloud clusters. For example, TBB values of $-80^{\circ} \mathrm{C},-60^{\circ} \mathrm{C}$, and $-40^{\circ} \mathrm{C}$ approximately correspond to the cloud tops at pressure levels (altitudes) of $100 \mathrm{hPa}(16 \mathrm{~km}), 175 \mathrm{hPa}$ $(13 \mathrm{~km})$, and $250 \mathrm{hPa}(11 \mathrm{~km})$, respectively. The period that each cloud cluster passed over Sumatera in Fig. 6 is also shown in the top of this panel.

CC2 was observed from 0900 UTC 04 May to 0100 UTC 05 May. The minimum TBB in CC2 remained at $\sim-80^{\circ} \mathrm{C}$ during this period. A large cloud area with $\mathrm{TBB}$ of $-80^{\circ} \mathrm{C}$ occurs at 1200 and 1800 UTC (e.g., a lump of cloud over Sumatera in Fig. 5a). This denotes the sudden development of CC2 twice over Sumatera. The TBB increases to $-60^{\circ} \mathrm{C}\left(-40^{\circ} \mathrm{C}\right)$ for 3 hours $(6$ hours).

CC3 appears at 0100 UTC 05 May and lasts until 2100 UTC. Overall, TBB in CC3 is distributed over the wide range of -60 and $-20^{\circ} \mathrm{C}$. This is associated with a reduction in the active region in SCC3, described in Section 4. CC4, with TBB below $-50^{\circ} \mathrm{C}$, gradually decays after 2300 UTC 05 May.

Figure 9a presents the time-height section of the vertical $p$-velocity at 6 -hourly intervals, calculated from upper sounding data at KT, KL and JB (see Fig. 1a). The time variation of di-

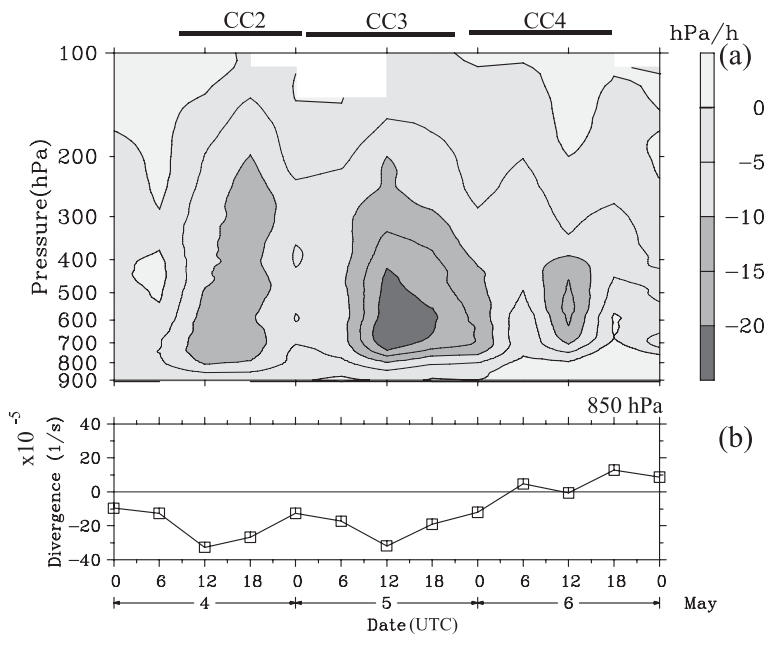

Fig. 9. a) Time-pressure section of the vertical $p$-velocity and $\mathrm{b}$ ) time variation of divergence at 850 -hPa level, calculated from 6-hourly upper sounding data at KT, KL, and JB during 04-06 May.

vergence at $850-\mathrm{hPa}$ level is also shown in Fig. $9 \mathrm{~b}$. At low levels, two maxima of convergence are seen at 1200 UTC 04 May (in CC2) and on 05 May (in CC3), respectively. Their amplitudes are approximately $32 \times 10^{-5} \mathrm{~s}^{-1}$. Comparing Fig. 9b with Fig. 7, we see that the convergence found in $\mathrm{CC} 2$ is primarily contributed by the diurnal variation of the low-level zonal wind between $\mathrm{KT}$ and $\mathrm{JB}$, while that in $\mathrm{CC} 3$ is mainly produced by the WWB at KT. Note that the low-level meridional wind in these stations is not strong at the occurrence of intense convergence (not shown here). The low-level convergence changes to weak divergence in $\mathrm{CC} 4$, after the arrival of WWB at JB.

During the passage of SCC3, updrafts are prominent in the whole troposphere. In CC2 and CC3, strong updrafts occur in the layer between $200-800 \mathrm{hPa}$ in association with the intense convergence at low levels. In CC4, strong updraft region is limited to the layer of $400-$ $700 \mathrm{hPa}$ at $1200 \mathrm{UTC} 06$ May.

The amplitude of updraft in CC3 is larger than the one in $\mathrm{CC} 2$, but the cloud activity of CC3 is weaker than that of CC2 (see Fig. 8). From Fig. 5c, an active region of SCC3 (CC3) is located only in/around western Sumatera when the strongest updraft occurs in association with the WWB. This fact suggests that the WWB 

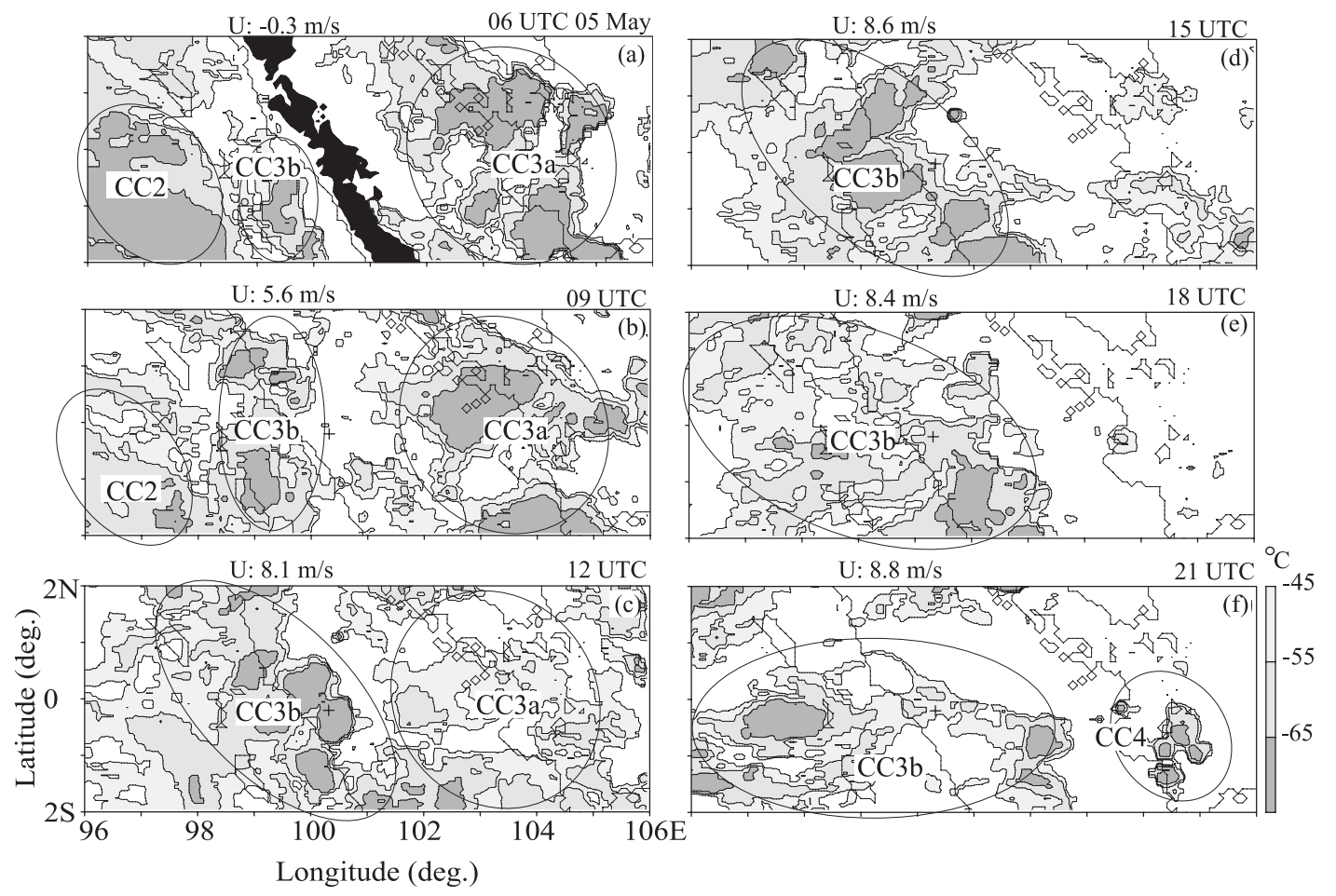

Fig. 10. 3-hourly maps of TBB in/around Sumatera from 0600 UTC to 2100 UTC 05 May. The shaded area in the panel of 0600 UTC indicates the mountainous area higher than $500 \mathrm{~m}$. An ellipse indicates CC2, CC3a, CC3b, and CC4. The spatial resolution of TBB data is $0.05^{\circ}$ grids. The low-level zonal wind from BLR data at KT is shown in the top of each panel.

causes significant updrafts forced by the mountain range, but the updraft regions are limited in/around western Sumatera.

In the subsequent section, we will discuss the evolution of CC3 in relation to the WWB and the orographic effect of the mountain range.

\section{Orographic effect of the mountain range on the WWB}

\subsection{Evolution of CC3 associated with the $W W B$}

Figure 10 presents 3-hourly maps of TBB in/ around Sumatera from 0600 UTC to 2100 UTC 05 May. The mountainous area higher than $500 \mathrm{~m}$ is indicated by the shaded area in panel (a). To investigate the evolution of CC3 in relation to the WWB, the low-level zonal wind averaged over altitudes of $1.5-2.0 \mathrm{~km}$, obtained from BLR at $\mathrm{KT}(+)$, is also shown in the top of each panel.

As can be seen from this figure, the westward propagation of CC3 seen in Fig. 6 is character- ized by the substitution of an active cloud region (CC3a) in eastern Sumatera for another one (CC3b) in western Sumatera. At 0600 UTC, when the low-level zonal wind is small at KT, CC3a dominates around the east coast of Sumatera in association with the background updraft in Fig. 9a (Fig. 10a). At this time, CC3b appears in the western inshore region of Sumatera. It is distinguished from the large cloud system (CC2) over the eastern Indian Ocean.

At 0900-1200 UTC, CC3b develops over the western coastal and mountainous regions with the increase of the low-level westerly wind, while CC3a begins to decay (Figs. 10b-c). After 1500 UTC, CC3b extends westward from the mountain range, and it gradually weakens (Figs. 10d-e). The dominant cloud region over the mountain range disappears until 2100 UTC (Fig. 10f).

Here, we discuss how the migration of WWB influenced the evolution of CC3b. The true ar- 
rival time of WWB at $\mathrm{KT}$ was at $0700 \mathrm{UTC} 05$ May (as will be shown in Fig. 12b later), while the arrival time of WWB was at 0600 UTC 06 May at JB, where is located in eastern Sumatera (see Fig. 7). The migration speed $\left(4.5 \mathrm{~m} \mathrm{~s}^{-1}\right)$ of WWB over Sumatera was approximately half that $\left(8.7 \mathrm{~ms}^{-1}\right)$ over the sea region between JB and KC in Fig. 7. If the WWB had traveled steadily at the faster speed characteristic of the sea region while over the Indonesian Maritime Continent, it would have reached JB $\sim 12$ hours before the actual arrival time. The time lag of WWB at JB was nearly equal to the retention time of $\mathrm{CC} 3 \mathrm{~b}$ over the mountain range (0900-1800 UTC 05 May). This strongly supports the view that the eastward migration of WWB is intercepted by the mountain range for a long time, as reported by Nitta et al. (1992).

From these factors, we conclude that the development of CC3b occurs due to the mountain range's interception of WWB, whose disappearance is associated with the termination of the interception.

\subsection{Wind and precipitation behaviors associated with SCC3 in / around the mountain range}

Vertical profiles of zonal wind from upper soundings at PD and KT are presented in Fig. 11 to illustrate the influence of the mountain range on the WWB. Figure 11a shows the WWB at PD at 0600 UTC 05 May. The arrival of WWB at PD precedes the development of $\mathrm{CC} 3 \mathrm{~b}$ around the mountain range (see Fig. 10a). The WWB had a maximum speed of $10 \mathrm{~ms}^{-1}$ near the surface, decreasing with height.

At 1200 UTC, when CC3b developed significantly over the mountain range, the maximum speed of the WWB increased to $18 \mathrm{~ms}^{-1}$ and its peak height ascended to $1.0 \mathrm{~km}$ at PD (Fig. 11b). The peak height of the WWB observed at KT was $2.5 \mathrm{~km}$. The difference of the peak height between PD and KT indicates the ascent of the WWB region intercepted by the mountain range.

Next, features of precipitation in relation to the WWB are studied using X-band weather radar data at KT. Figure 12a presents the zonal distribution of the maximum reflectivity echo over the region extending $15 \mathrm{~km}$ north and
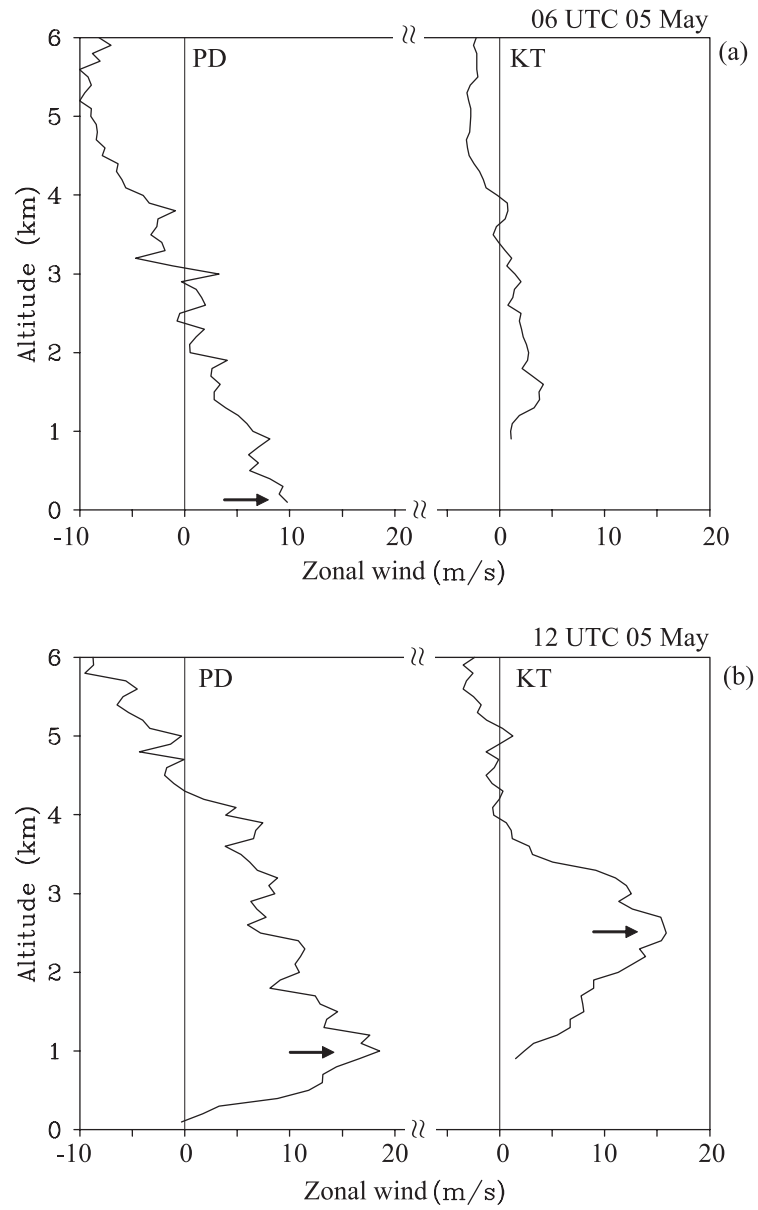

Fig. 11. Vertical profiles of zonal wind from upper sounding data at PD and KT at a) 0600 UTC and b) 1200 UTC 05 May. The arrow is the peak height of WWB.

south of the radar site at an altitude of $3 \mathrm{~km}$. The time variation of zonal wind averaged over an altitude range of $1.5-2.0 \mathrm{~km}$, from BLR, is also indicated in Fig. 12b. At KT, CC3b develops and sustains during 1100-2000 UTC as shown by a solid line in the left of panel (a).

In Fig. 12a, it is noticeable that precipitation echoes ( $>30 \mathrm{dBZ})$ appear before the development of $\mathrm{CC} 3 \mathrm{~b}$ around the mountain range. From 0100 UTC, the intense precipitation echoes gradually extend eastward from the coastal area $(\sim 50 \mathrm{~km}$ west from the radar site). At 0700 UTC, the eastern edge of precipitation echoes reaches KT with the appearance of WWB (Fig. 12b). The intense precipitation 


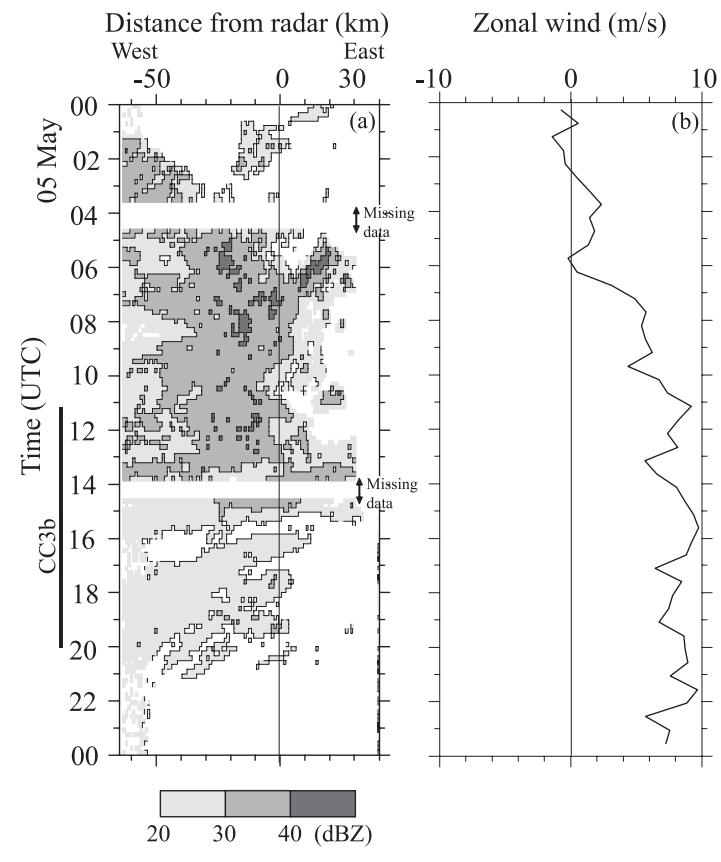

Fig. 12. Time series of (a) zonal distribution of the maximum reflectivity echo over the region, extending $15 \mathrm{~km}$ north and south of the weather radar site at an altitude of $3 \mathrm{~km}$, and (b) low-level zonal wind averaged over altitude range of $1.5-2.0 \mathrm{~km}$, from $\mathrm{BLR}$, on 05 May. The data interval of reflectivity echo is $10 \mathrm{~min}$, while the time average of low-level zonal wind is $30 \mathrm{~min}$. The analysis area in panel (a) is indicated by the rectangular box of Fig. 1b. The development period of CC3b over KT is shown by a solid line in the left of panel (a).

area remains stationary to the west of the radar site until 1400 UTC. From the wind profile at PD (Fig. 11a), the stationary precipitation is considered to be caused by a forced lifting over the western slope of the mountain range due to the lowest-level intense westerly wind.

After 1400 UTC, the stationary precipitation weakens, although CC3b develops over the mountain range. The weakening of precipitation echoes would be due to the decrease of the lowest-level westerly wind with the ascent of the peak height of the WWB as shown in Fig. $12 \mathrm{~b}$.

Figure 13 presents time-altitude sections of a) reflectivity from BLR, and b) vertical velocity and c) zonal wind from EAR, during the same
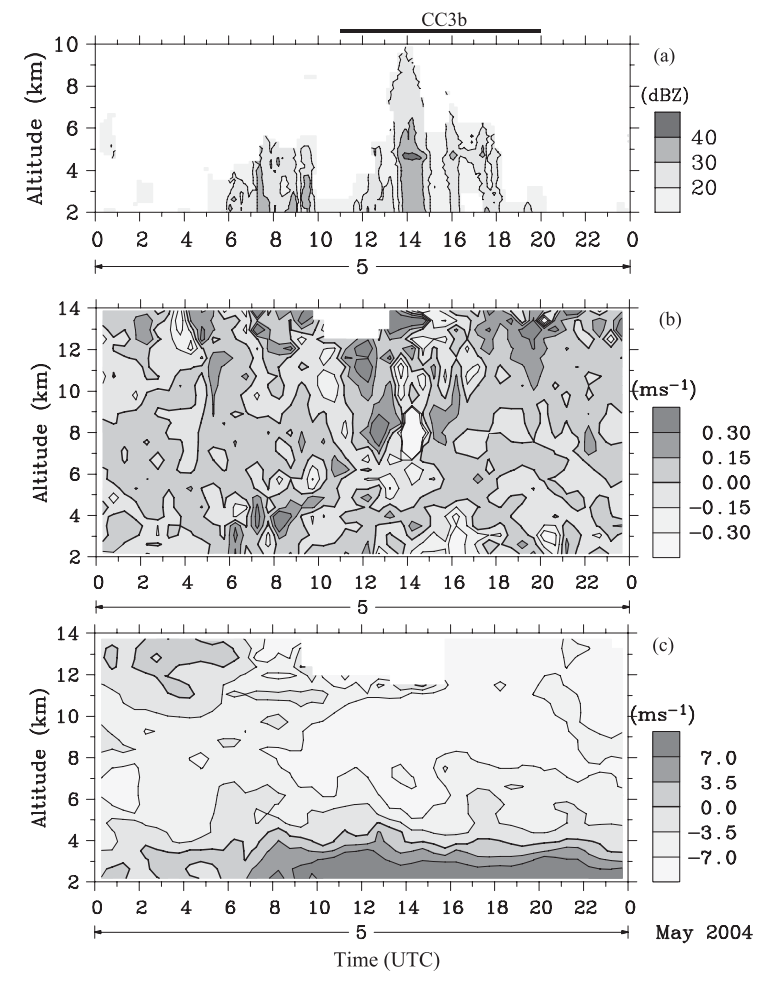

Fig. 13. Time-altitude sections of (a) precipitation echoes from BLR, and (b) vertical velocity and (c) zonal wind from EAR on 05 May. Time average of BLR data is $10 \mathrm{~min}$, while that of EAR data is $30 \mathrm{~min}$.

period. In Fig. 13a, a shallow precipitation with an echo top at $\sim 5 \mathrm{~km}$ is seen in the period of 0600-1000 UTC 05 May. This indicates the vertical structure at the eastern edge of stationary precipitation (see Fig. 12a). Strong updrafts are present inside the shallow precipitation (Fig. 13b), which represent the orographic lifting due to the lowest-level westerly wind, mentioned above.

After 1100 UTC, strong updrafts associated with CC3b are distributed above an altitude of $7 \mathrm{~km}$. Stratiform precipitation systems with a melting layer at an altitude of $5 \mathrm{~km}$ are observed under the updraft regions inside CC3b.

The WWB (>7 $\mathrm{ms}^{-1}$ ) seen in Fig. $12 \mathrm{~b}$ extends to an altitude of $\sim 3 \mathrm{~km}$ (Fig. 13c). Above that level, an environmental easterly wind intensifies in association with the occurrence of WWB. The intensification of the environmental easterly wind causes the westward extension of 
CC3b from the mountain range (see Figs. $10 \mathrm{~d}-\mathrm{e})$.

\section{Conclusions}

Intensive upper sounding observation was conducted at seven stations in/around Sumatera from 10 April to 09 May 2004, as a part of the first campaign of CPEA project (CPEA-I), and simultaneous observations were made with weather radar and wind profilers at KT, West Sumatera. Between 04 and 07 May, a super cloud cluster (SCC) with a westerly wind burst (WWB) propagated eastward over the Indonesian Maritime Continent. Its evolution and the associated wind behavior are studied, using GOES-9 IR data and CPEA observations, and are discussed in this report.

During the analysis period, this SCC developed significantly over the eastern Indian Ocean, decayed rapidly over Sumatera, and then re-developed over Kalimantan. The eastward propagation of the SCC resulted from the successive formation of meso-scale cloud clusters with westward propagation. The transition of the SCC is related to the evolution of these cloud clusters.

Three cloud clusters (CC2, CC3, and CC4) appeared over Sumatera at one-day intervals during the passage of SCC. Examination of upper sounding data from western and eastern Sumatera indicates that the evolution of CC2 was driven by the diurnal variation of low-level zonal wind, while that of CC3 and CC4 was influenced by the WWB over Sumatera. After the WWB arrived at a mountain range in western Sumatera, the active region of CC3 diminished, but it dominated in/around the mountain range for $\sim 9$ hours. CC4 decayed during the passage of the WWB over Sumatera.

It was found from upper sounding data along the equator that the migration speed of the WWB over Sumatera was approximately half that over the sea region between Sumatera and Kalimantan, due to the orography of the Indonesian Maritime Continent. In western Sumatera, the peak height of the WWB at the mountain range ascended $1.5 \mathrm{~km}$ from that on the windward side. This shows that the eastward migration of WWB was intercepted by the mountain range. The orographic influence on the WWB is considered to persist during the retention of $\mathrm{CC} 3$ in its vicinity.
Using ground-based radar observation data, we demonstrate orographic precipitation associated with the WWB on the western slope of the mountain range, and the detailed wind structure inside the SCC over the mountainous region.

In the present study, the orographic influence of Sumatera on the WWB in relation to the evolution of the SCC was mainly investigated as mentioned above. During the CPEA campaign, we also found other SCCs (SCC1 and SCC2) with weak westerly wind at low levels, which dissipated to the east of Sumatera. In the future, additional studies of the evolution of SCCs in different wind conditions over Sumatera are needed, and will be pursued with the CPEA special observation data and a numerical model experiment.

\section{Acknowledgments}

The authors are grateful to two anonymous reviewers and Dr. Y.-M. Kodama of Hirosaki University for their valuable comments on the manuscript. We also thank Prof. T. Kikuchi of Kochi University for providing GOES-9 IR data. The OLR data was also provided by the National Oceanic and Atmospheric Administration (NOAA). Radar instruments at KT have been operated by staff from the Institute of Aeronautics and Space of Indonesia (LAPAN), the Agency for the Assessment and Application of Technology (BPPT), and the Meteorological and Geophysical Agency (BMG). The present study was partially supported by a Grant-inAid for Scientific Research on Priority Area764 of the Ministry of Education, Culture, Sports, Science, and Technology (MEXT) of Japan.

\section{References}

Fukao, S., 2006: Coupling processes in the equatorial atmosphere (CPEA): A project overview. J. $\mathrm{Me}$ teor. Soc. Japan, this issue.

-, H. Hashiguchi, M. Yamamoto, T. Tsuda, T. Nakamura, M.K. Yamamoto, T. Sato, M. Hagio, and Y. Yabugaki, 2003: Equatorial atmosphere radar (EAR): System description and first results. Radio Sci., 38(3), 1053, doi:10.1029/2002RS002767.

Kawashima, M., Y. Fujiyoshi, M. Ohi, T. Honda, T. Kozu, T. Shimomai, and H. Hashiguchi, 2006: Overview of Doppler radar observations of precipitating cloud systems in Sumatera Island 
during the first CPEA campaign. J. Meteor. Soc. Japan, this issue.

Lau, K.-M., T. Nakazawa, and C.H. Sui, 1991: Observations of cloud cluster hierarchies over the tropical western Pacific. J. Geophys. Res., 96, 3197-3208.

Madden, R.A. and P.R. Julian, 1994: Observations of the 40-50-day tropical oscillation-A review. Mon. Wea. Rev, 122, 814-837.

Murata, F., M.D. Yamanaka, H. Hashiguchi, S. Mori, M. Kudsy, T. Sribimawati, B. Suhardi, and Emrizal, 2006: Dry intrusions following eastward-propagating synoptic-scale cloud systems over Sumatera Island. J. Meteor. Soc. Japan, 84, 277-294.

Nakazawa, T., 1988: Tropical super clusters within intraseasonal variations over the western $\mathrm{Pa}-$ cific. J. Meteor. Soc. Japan, 66, 823-839.

Nitta, Ts., and S. Sekine, 1994: Diurnal variation of convective activity over the tropical western Pacific. J. Meteor. Soc. Japan, 72, 627-641.

—, T. Mizuno, and K. Takahashi, 1992: Multiscale convective systems during the initial phase of the 1986/87 EI Nino. J. Meteor. Soc. Japan, 70, 447-466.

O'Brien, J.J., 1970: Alternative solutions to the classical vertical velocity problem. J. Appl. Meteor., 9, 197-203.
Rui, H. and B. Wang, 1990: Development characteristics and dynamic structure of tropical intraseasonal convection anomalies. J. Atmos. Sci., 47, 357-379.

Seto, T.H., M.K. Yamamoto, H. Hashiguchi, and S. Fukao, 2004: Convective activities associated with intraseasonal variation over Sumatera, Indonesia observed with the equatorial atmosphere radar. Ann. Geophys., 22, 3899-3916.

Shibagaki, Y., T. Shimomai, T. Kozu, S. Mori, Y. Fujiyoshi, H. Hashiguchi, M.K. Yamamoto, S. Fukao, and M.D. Yamanaka, 2006: Multi-scale aspects of convective systems associated with an intraseasonal oscillation over the Indonesian Maritime Continent. Mon. Wea. Rev., 134, 1682-1696.

Sui, C.-H. and K.-M. Lau, 1992: Multiscale phenomena in the tropical atmosphere over the Western Pacific. Mon. Wea. Rev., 120, 407430.

Teshiba, M., H. Hashiguchi, S. Fukao, and Y. Shibagaki, 2001: Typhoon 9707 observations with the MU and L-band boundary layer radar. Ann. Geophys., 19, 925-931.

Weickmann, K.M. and S.J.S. Khalsa, 1990: The shift of convection from the Indian Ocean to the Western Pacific Ocean during a 30-60 day oscillation. Mon. Wea. Rev., 118, 964-978. 